Asian Spine Journal Vol. 6, No. 1, pp 71 87, 2012

http://dx.doi.org/10.4184/asj.2012.6.1.71

\title{
Metastatic Spinal Tumor
}

\author{
Chong-Suh Lee, Chul-Hee Jung \\ Department of Orthopaedic Surgery, Spine Center, Samsung Medical Center, \\ Sungkyunkwan University School of Medicine, Seoul, Korea
}

\begin{abstract}
In accordance with extending survival periods of cancer patients, number of consecutively developing metastatic spinal tumor is also increasing. There have been improvements in the treatment results of metastatic spine tumor by virtue of the developments in diagnostic radiology, chemotherapy, adjuvant treatment, operative device and technique, discrete preoperative plan, and standardized operation. Accordingly, surgical indication has also increased. Clinically, in case of metastatic spine tumor,treatment of tumor itself should be focused on pain relief, preservation of neurologic function, prevention of pathologic fracture, prevention of pathologic fracture, and correction of spinal instability for improving quality of life, rather than for extension of survival. Additionally, etiology of spinal tumor,correct diagnosis and subsequent treatment principles should be thoroughly understood before establishing treatment plans for effective treatments.
\end{abstract}

Key Words: Spine, Metastasis, Neoplasm

\section{Introduction}

In accordance with extending survival periods of cancer patients, number of developing metastatic spinal tumor is also increasing. Ratio of developing spinal metastasis in case of the patients having history of malignant tumor has been reported up to $30-90 \%$ based on autopsy. About $20 \%$ of spinal metastasis cases exhibit neurologic deficit due to spinal cord compression. Regarding metastatic spinal tumor in patients with neurologic deficit, having 3 months or more expected lifetime, a common view shared by most of the cardiologists is the performance of surgery. Despite, there is no consensus on this matter between spine surgeons and radiotherapists.

Since various treatment methods have been used for spine tumor, no unified diagnosis and treatment procedures accepted by spine surgeons have been established yet. Nevertheless, treatment results of metastatic spine tumor have been enhanced by virtue of the developments in diagnostic radiology, surgery, chemotherapy and adjuvant treatment as well as discrete preoperative plan, and standardized operation. Additionally, etiology of spinal tumor, correct diagnosis, and subsequent treatment principles should be effusively understood before establishing treatment plans for effective treatments [1].

About 2/3rd of the malignant tumor cases develop metastasis, and the incidence of malignant tumor is consecutively increasing every year. The skeletal system is the third most common site of metastasis, and the spine is the most common site of metastasis. In the spine, the vertebral body is the most common site of metastasis but according to plain radiographs, changes in pedicle is observed at the earliest time, and metastasis development in the posterior element claims about $15 \%$ of the total spinal metastasis [2,3]. Skeletal metastasis develops in every kind of malignant tumor, but most frequently does in breast cancer followed by prostate cancer, thyroid cancer, lung cancer, and renal cell cancer. Prostate cancer and bronchial cancer are most common

Received Jan 9, 2012; Revised Feb 7, 2012; Accepted Feb 8, 2012

Corresponding author: Chong-Suh Lee, MD

Department of Orthopaedic Surgery, Spine Center, Samsung Medical Center,

Sungkyunkwan University School of Medicine, 81 Irwon-ro, Gangnam-gu, Seoul 135-710, Korea

Tel: +82-2-3410-3509, Fax: +82-2-3410-0061, E-mail: cs13503@skku.edu

Copyright (C) 2012 by Korean Society of Spine Surgery

作 which permits unrestricted non-commercial use, distribution, and reproduction in any medium, provided the original work is properly cited. Asian Spine Journal • pISSN 1976-1902 eISSN 1976-7846 
in male when compared with breast cancer in female, and neuroblastoma in youngsters.

In the past, developments in medical treatments for cancer have contributed to enhanced survival, and developments in operative devices and operative techniques have resulted in an increased postoperative survival rate, and a decreased complication rate and accordingly, expanded indications of operation.

Clinically, in case of metastatic spine tumor, treatment of tumor itself should be focused on pain relief, preservation of neurologic function, prevention of pathologic fracture, prevention of pathologic fracture, and correction of spinal instability for improving quality of life, rather than extension of survival.

\section{Pathophysiology}

Skeletal metastasis of malignant tumor is known to be affected by three specific factors. The first factor is metastasis pathway, which includes the arterial system, direct invasion, lymphatics, and venous system. Among these four pathways, metastasis via venous system is the most common route of spinal metastasis. Since venous embolization of tumor passes natural filters such as lung, liver and bone marrow, spinal metastasis occurs after the primary metastasis passes to the lung or liver, or through other routes. Lung cancer can be metastasized directly via segmental artery of spine while breast cancer or prostate cancer can develop spinal metastasis via Baston [4] plexus. The second factor is tissue receptivity on tumor emboli. Some tissues provide tumor emboli with good environment for survival. The "seed and soil" theory supports the hypothesis that bone marrow of spine provides tumor emboli with biochemically and hemodynamically favorable environment for implantation. Practically, red marrow of vertebral body has affinity for tumor emboli and accordingly, implantation and growth of tumor cells are easily accomplished. The third factor is the intrinsic factor of tumor cells, which helps survival and proliferation of a certain kind of cells in marrow, which is more advantageous than other cells. For example, prostaglandin and osteoclast activating factors secreted from breast cancer cells induce bone resorption resulting in destructive bone metastasis [5], and these cells might demonstrate a feature of formation of fibrin membrane to protect the formed nidus.

Roughly, 5-30\% of metastatic lesion of spine shows neurologic symptoms. The most common mechanism of
Table 1. Mechanism of neurologic deficit in metastatic spinal tumor

\begin{tabular}{l}
\hline Mechanical compression \\
Direct compression by tumor \\
Displacement of the bone fragment \\
Kyphotic deformity \\
Spinal malalignment \\
Vascular imcompetence \\
Ischemia due to arterial embolism \\
Edema due to venous congestion \\
\hline
\end{tabular}

neurologic symptoms is the mechanical compression by the lesion, which develops in the bone, and may develop even without any vertebral body collapse. Other mechanisms may include kyphosis due to compression fracture of vertebral body, or mechanical cord compression due to the malalignment caused by posterior displacement of bone fragments, subluxation or dislocation. Additionally, neurologic symptoms due to the vascular compromise of spinal cord may also appear. Vascular insufficiency includes underlying mechanism of ischemia of spinal cord due to segmental artery occlusion by tumor emboli, venous thrombus caused by venous congestion, and spinal cord injury due to edema caused by internal hemorrhage of spinal cord (Table 1).

\section{Clinical Considerations}

Clear understanding about factors affecting the general conditions of patients, treatment and prognosis is most important in the process of treating metastatic spine tumor [68].

\section{Original tumor}

Stage of development of original tumor during spinal metastasis is an important factor for deciding a treatment method. According to the type of original tumor, susceptibility on radiotherapy and medication is different. For example, since renal cell carcinoma or thyroid cancer has plenty of vascularity, preoperative arterial embolization can be applied.

\section{Neurologic deficit}

In general, rapidly progressive paraplegia without a history of trauma develops mainly due to metastatic spine tumor, and paraplegia appearing within 1-2 days shows a poor prognosis regardless of modality of treatments. In ac- 
cordance with the activity level of patients when diagnosis of metastatic spine tumor is made, postoperative ambulatory status is decided [9].

\section{Deformity and instability of spine}

The deformity or instability of spine is a mechanical compression of spine cord, which is a factor involved in the development of progressive neurologic deficit. In such a case, surgical immobilization may be necessary in addition to radiotherapy or administration of medication.

\section{History of previous treatment}

Knowing patients' prior treatments helps in understanding the nature of the lesion and sensitivity of treatment. When a patient has a history of prior radiotherapy, additional radiotherapy cannot be performed in case of developing a neurologic deficit, but surgical treatment should be considered first. In case of patients who have taken chemotherapy or steroids for a long period of time, risk of postoperative infection may be high.

\section{General condition}

When a patient has preoperative anemia, thrombocytopenia, coagulopathy, hyperproteinemia or hypercalcemia, severe complications may develop and accordingly, preoperative corrections are required.

\section{Expected survival}

Factors affecting expected survival include type of primary tumor, presence of multiple metastases and degree of neurologic deficit. There is a controversy on the topic about the necessity of surgical treatment based on the expected survival $[10,11]$. Recently, survival rate, as an indicator for surgery has been shortened, because more active treatments are emphasized than before. In general, in case of the primary cancer such as stomach cancer, liver cancer and lung cancer, expected survival is short, while cases of breast cancer, renal cell carcinoma, and prostate cancer show long expected survival [12].

\section{Diagnosis}

\section{Clinical manifestations}

The most common symptom of spine tumor is axial pain with occasional radiculopathy. Axial pain develops due to direct effect of tumor, cortical breakage and spinal cord compression. Unlike primary back pain, axial pain does not respond to conservative treatments but progressively deteriorates. Axial pain is not associated with patients' position or activity level, and is not alleviated during periods of rest. In addition, percussion tenderness and nocturnal pain are the characteristics of axial pain. In case of pathological fracture due to cortical invasion or development of pathologic fracture or instability, pain gets aggravated due to mobility. Pain-associated scoliosis may appear, and this type of deformity demonstrates the difference between acute progression and idiopathic scoliosis. Early diagnosis and adequate treatments may prevent deformity, but once deformity develops, surgical treatments are often required [13].

Neurologic deficits are often found in malignant lesions rapidly progressing in association with location of tumor and malignancy of the cell. In case of a cervical lesion, neurologic impairment progresses slowly, but in case of thoracolumbar lesion, deterioration of neurologic deficit is fast. About $60 \%$ of neurologic deficits cases show myelopathy or radiculopathy, $30 \%$ demonstrates muscle weakness, and less than 3\% exhibit impairment of spinchter function.

Causes of the above developments include pathologic fracture, transfer of tumor to adjacent soft tissues, root invasion, mechanical instability and spinal cord compression. Once neurologic deficit develops, low recovery rate can be expected. Therefore, early diagnosis and treatment is important.

\section{Documentation of patient's history and Physical examinations}

Documentation of history and physical examination should be conducted for all the patients suspected of spinal tumor. Detailed history about the location and nature of pain, aggravating and relieving factors and changes with time course, and careful evaluation about the presence of systemic malignancy should be conducted. In addition to direct inspection and percussion on the spine, detailed neurologic examinations including vocalization, cranial motor, balance of motor and sensory nerve, and reflex of the ex- 
tremities and trunk are also required. Patients with findings of neurologic deficits are required to be checked by neurologists for differential diagnosis of neurogenic disease.

\section{Diagnostic work-up}

Routine tests required for spinal tumor patients are as following: Laboratory tests (blood lab): complete blood count $(\mathrm{CBC})$ with differential count, erythrocyte sedimentation rate, urinalysis, electrolyte, tumor marker, electrophoresis of serum and urine; plain radiographs of the lesion; whole body bone scan; computed tomography; myelography; magnetic resonance imaging; biopsy; additional study: positron emission tomography-computed tomography (PET-CT); angiography, etc.

\section{1) Laboratory tests}

Electrophoresis of serum and urine protein is useful for diagnosis of myeloma. Once hematopoietic function of bone marrow is deteriorated by metastasis to bone marrow, development of pancytopenia occurs. Leukocytosis means a leukemoid reaction of a secondary development of leukemia or disseminated cancer, and erythrocyte sedimentation rate may nonspecifically increase in case of metastatic spinal tumor and myeloma.

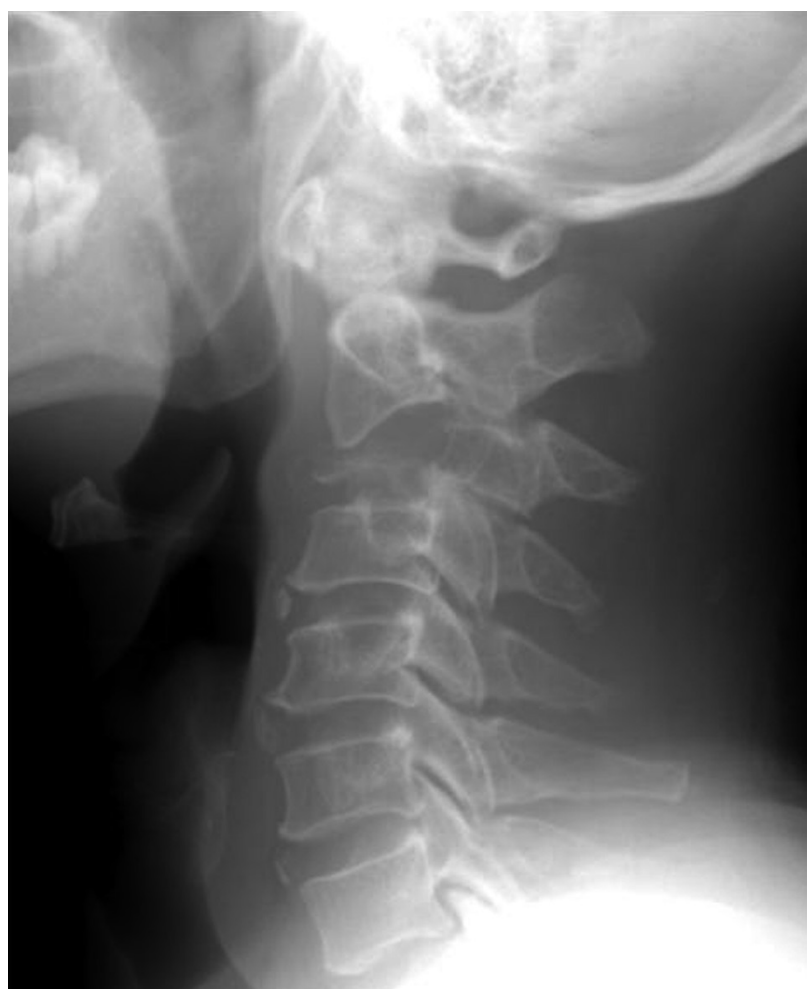

Fig. 1. Lateral plain radiograph of cervical spine. Radiolucency on $\mathrm{C} 3$ body with compression fracture is observed.
In case of metastatic tumor of spine, a tumor marker can be used for confirming a primary lesion. Increase in prostate specific antigen (PSA) is associated with prostate cancer, and an increase in carcinoembryonic antigen (CEA) is typically associated with colon cancer, however, increased levels of CEA can also be found in case of breast cancer. Alpha-fetoprotein $(\alpha-\mathrm{FP})$ may increase in case of hepatocellular carcinoma, and beta-human chorionic gonadotropin $(\beta-H C G)$ increases in a urogenital malignancy case.

\section{2) Plain radiographs}

Plain radiographs should be conducted whenever cancer is suspected $[14,15]$ and anterior-posterior and lateral views of spines should be basically taken. Upon observing any destruction in vertebral bodies and manifestations of bulging into the adjacent tissues, differentiation of benign from malignant tumors might be possible. Mechanical instability level may be recognized, but it is hard to confirm a smallsized lesion. Only when osteolysis progresses to $30-50 \%$, a small-sized lesion can be identified. Common findings of plain radiograph include radiolucency, bone erosion, compression fracture, soft tissue mass, and calcification (Fig. 1). Pedicle, which is mainly composed of cortical bones is clearly observed in anteroposterior (AP) view of X-ray, and in case of metastatic tumor, AP view is radiolucent due to

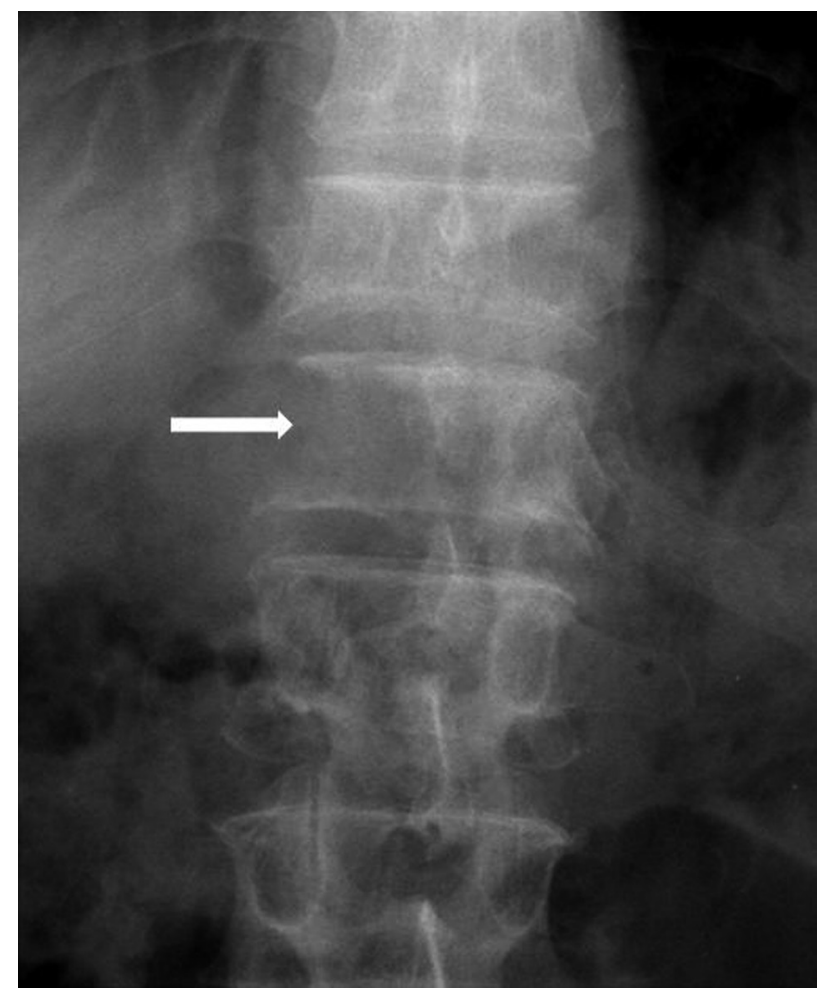

Fig. 2. 'Winking owl sign' due to osteolysis of right pedicle by $\mathrm{T} 12$ metastatic cancer. 


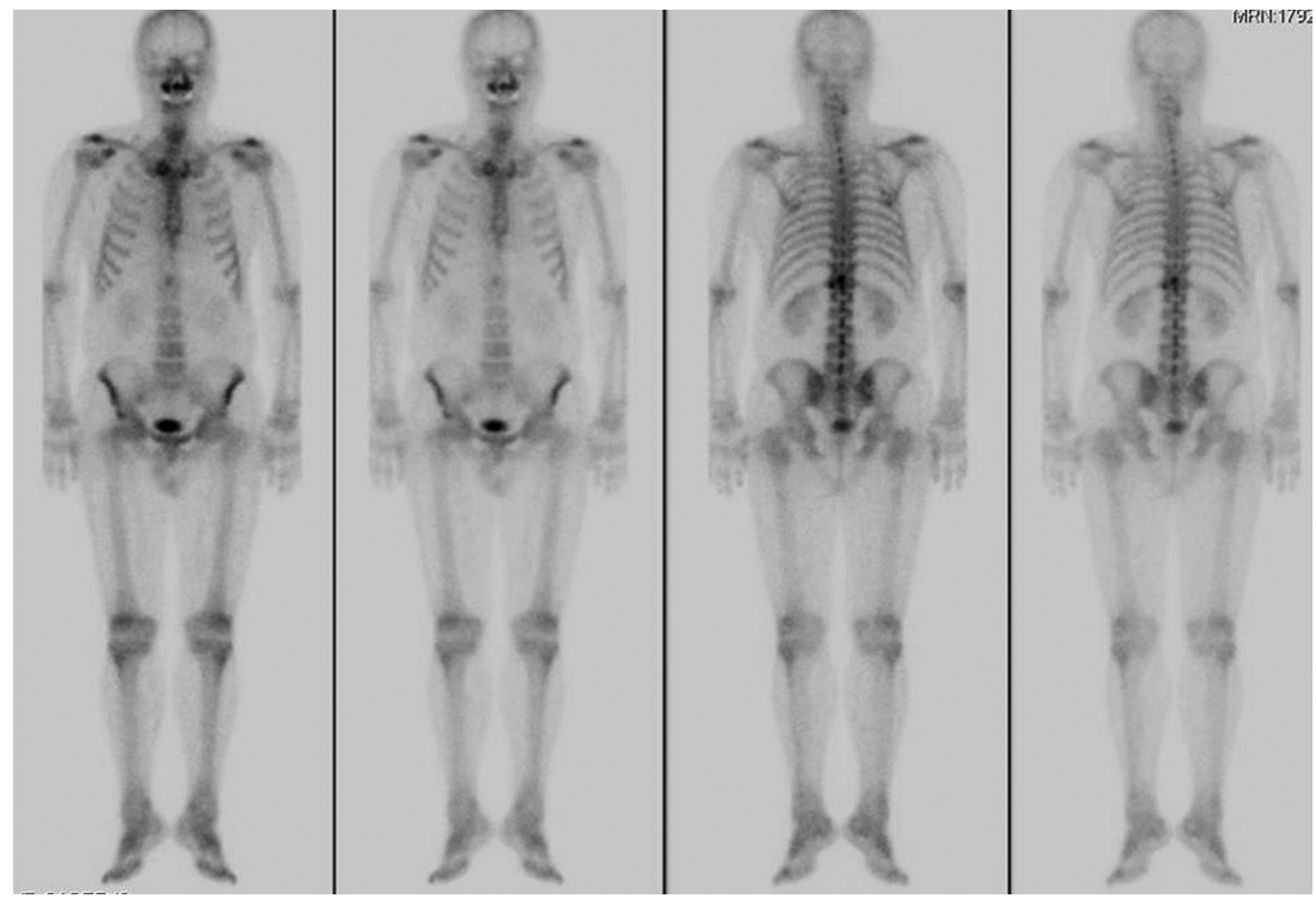

Fig. 3. A 63-year-old male patient with oral cavity cancer. His whole body bone scan shows metastasis to T12.

osteolysis in pedicle, and this is called as a "winking owl sign' (Fig. 2).

\section{3) Whole body bone scan}

With respect to bone scan using technetium- $99 \mathrm{~m}$, lesions can be confirmed prior to plain radiograph. In order to observe abnormal findings through plain radiograph, more than $30-50 \%$ of cancellous bones should be destructed and accordingly, whole body bone scan is the most sensitive test

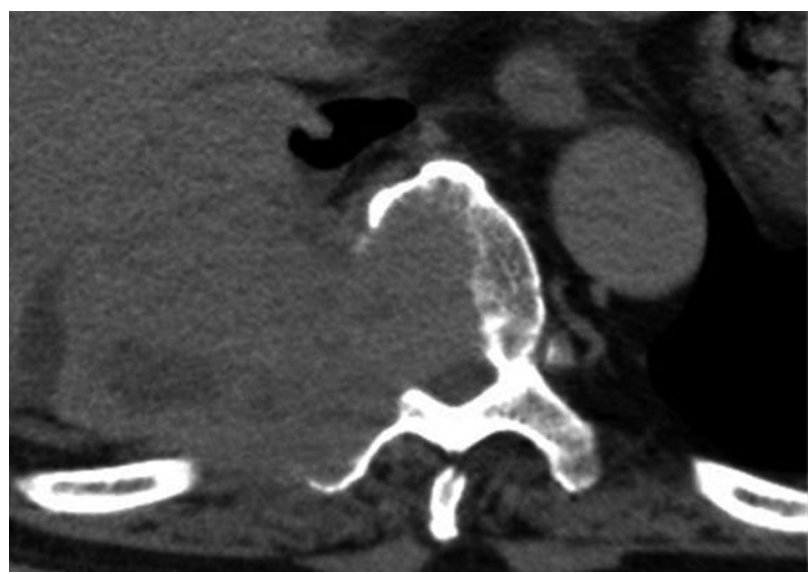

Fig. 4. Computed tomography scan of Giant cell tumor in T11. Tumor destructed vertebral body, pedicle and transverse process, and invasion to thoracic cavity and spinal canal. for early diagnosis of tumor [16]. This method is specifically sensitive for the areas with ostoid formation, thus enabling detection of up to a $2 \mathrm{~mm}$ sized lesion. Interpretation of the scans of elderly patients should be careful carried out, because a false positive can be revealed in cases of fracture, infection, and arthritis. In multiple myeloma, chordoma or decreased vascular response, and false negative may appear. Because of high sensitivity of whole body bone scan, it is useful for follow-up of patients who are suspected of metastasis of prior cancer (Fig. 3), based on plain radiograph.

\section{4) Computed tomography (CT) and CT-myelography}

The $\mathrm{CT}$ is more sensitive than plain radiograph in terms of detecting lesions prior to extensive bone destruction or marrow involvement because it can sensitively catch changes in bone density. Accordingly, CT is useful for understanding the level of cortical bone erosion, for preoperative test and for establishing a surgical plan (Fig. 4).

Before magnetic resonance imaging (MRI) was introduced, myelography was the standard test, but MRI is replacing myelography due to the possibility of development of complications caused by contrast media, and the associated drawbacks of invasive method. Myelography is used 
when MRI is not applicable due to implants, or in case of claustrophobia. When myelography and contrast enhanced $\mathrm{CT}$ are used together, CSF dynamics is well understood, and differentiation of intradural lesion from extradural lesion becomes easier.

5) MRI

Since MRI is non-invasive, safe and free from radiation exposure, it can be used in case of all the patients. Multidirectional MRI on the whole spine is available, and MRI is useful as a screening test for whole body metastatic spinal tumor. MRI is also useful for differentiating soft tissue invasion as well as hematoma, edema, and infection (Fig. 5). When contrast enhanced CT scan is used, invasion of adjacent structure of the spine can be more precisely differentiated than $\mathrm{CT}$ and in particular, it is useful for differentiating
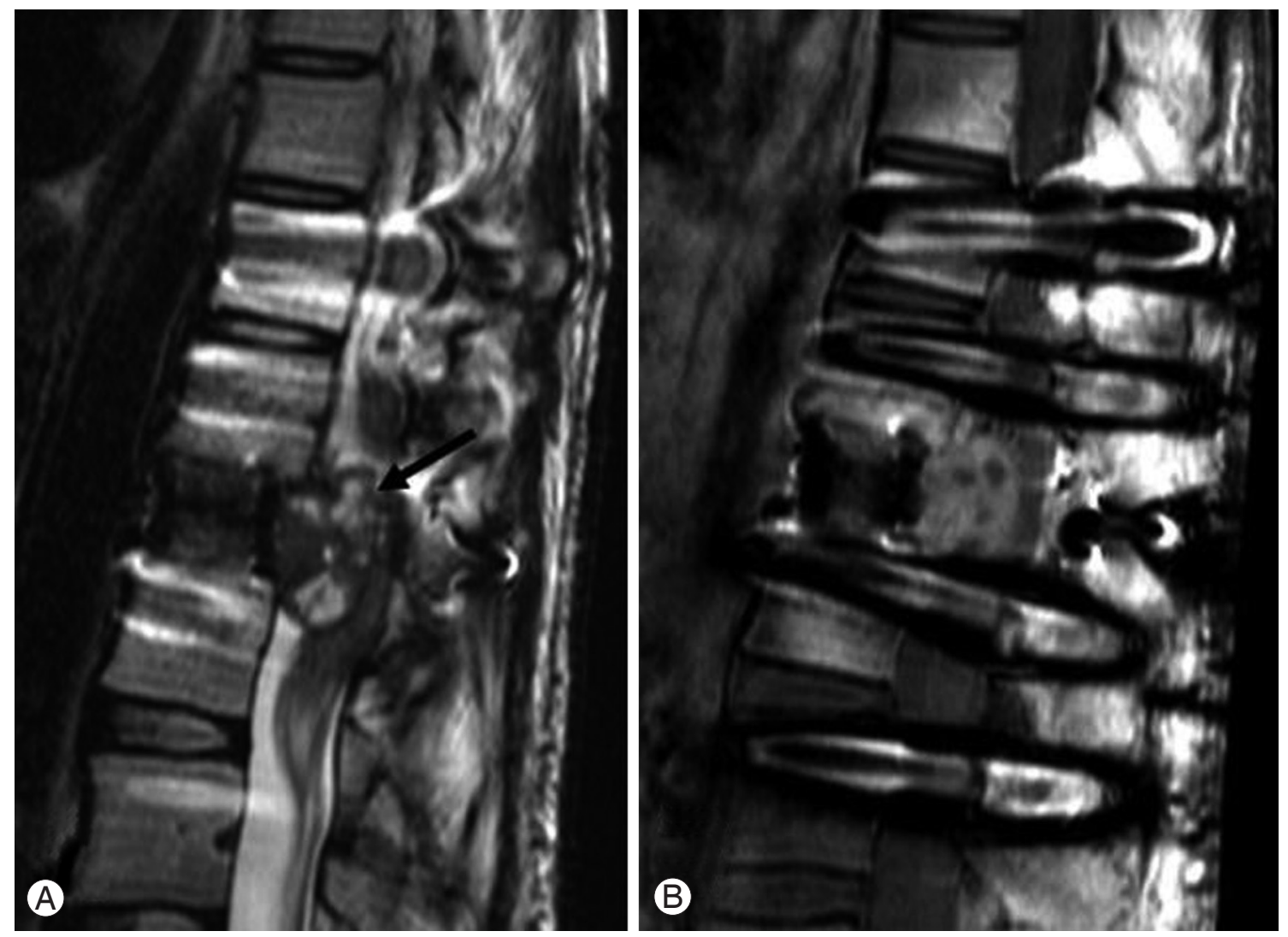

Fig. 5. Recurred giant cell tumor. (A) T2-weighted magnetic resonance imaging (MRI): recurred tumor (black arrow). (B) T1-weighted MRI with enhancement.
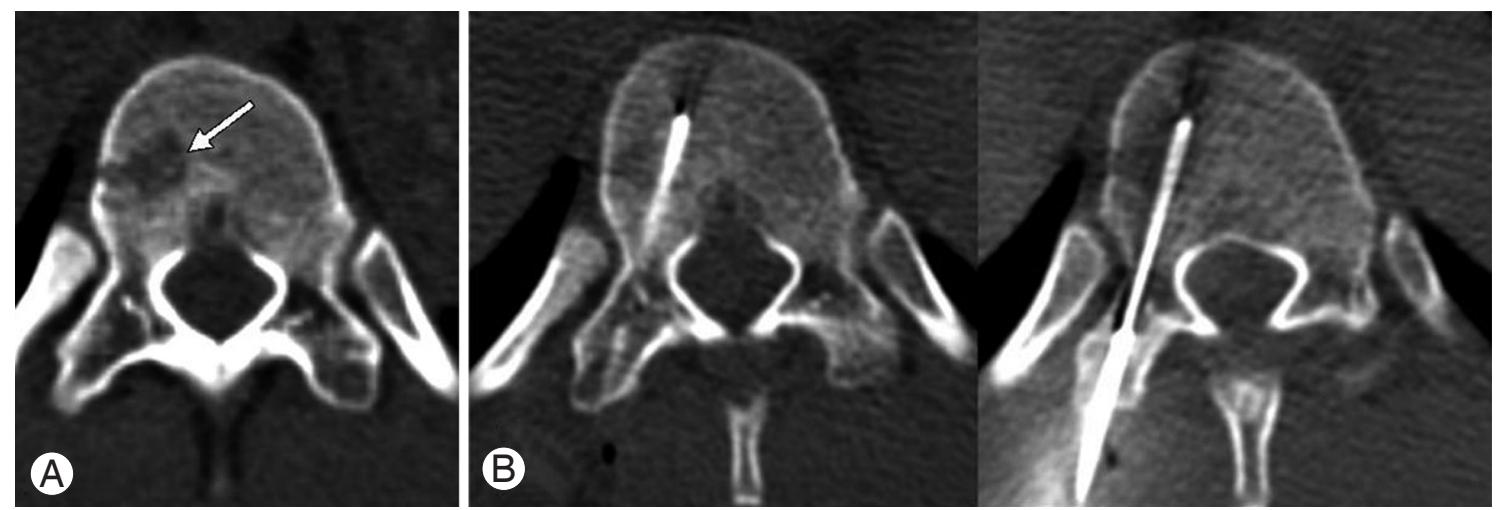

Fig. 6. Computed tomography guided biopsy. (A) Tumor at right vertebral body (arrow). (B) Biopsy was done by transpedicular approach. 
osteoporotic compression fracture from pathologic fracture caused by metastatic tumor [17].

\section{6) Biopsy}

Biopsy is an essential test for carrying out confirmative diagnosis, which is required in cases of considering an active treatment such as surgery. Unless an active treatment such as surgery is considered, biopsy is not recommended to a great extent, and when biopsy is conducted, a direct biopsy during surgery prior to definitive surgery is advantageous for patients. Biopsy methods include percutaneous needle biopsy, open incisional biopsy, and open excisional biopsy. In case of percutaneous needle biopsy, diagnostic accuracy is as low as $75 \%$ due to the small amount of the specimen, and risk of error involved in the biopsy procedure; but when conducted together with CT or ultrasonography, accuracy is enhanced up to $89 \%$ (Fig. 6). Open incisional biopsy and excisional biopsy should be designed as small as possible considering an additional operation, and surrounding tissues should be free from contamination.

\section{7) Angiography}

Angiography is not very often used for the diagnosis of spine tumor, but is helpful for establishing a surgical plan because relation between tumor and feeding vessel of tumor or adjacent major vessel can be understood. Moreover, since metastatic renal cell carcinoma, thyroid cancer, aneurismal bone cyst and hemangioma have rich vascularity of tumor itself thus resulting a risk of developing complications caused by massive bleeding, preoperative feeding artery embolization is performed (Fig. 7). However, attention is required in such cases because angiography is invasive, and spinal cord ischemia may develop at the spinal vascular critical zone.

8) F-18 fluorodeoxyglucose positron emission tomography (F-18 FDG PET)

The F-18 FDG PET is evaluated to help in selection of treatment plans, and ultimately enhance survival rates of patients by deciding stages of diseases as soon as possible through implementation of a one-time whole body scan (Fig. 8).

Even though PET has been widely used for assessing malignant tumors and their metastasis, its role in assessing primary or secondary tumor of bone, or tumor like lesion has is not well known. A number of studies have been conducted on utility of PET in assessing bone metastasis. PET is evaluated to be superior than the typical whole body bone scan in most of the cases of primary tumor. The reason is bone scan reveals bone metastasis in case of a secondary change induced by tumor, or of abundant osteoblastic reactions, while PET shows tumor itself and accordingly, PET is not associated with the presence of osteoblastic reactions [18].

\section{Staging}

Similar to the cases of tumor development in the musculoskeletal system, staging of spine tumor can be conducted, and staging is necessary for standardizing treatments according to stages of a disease, and eventually for enhancing efficacy of treatments. The purposes of classifying stages in-
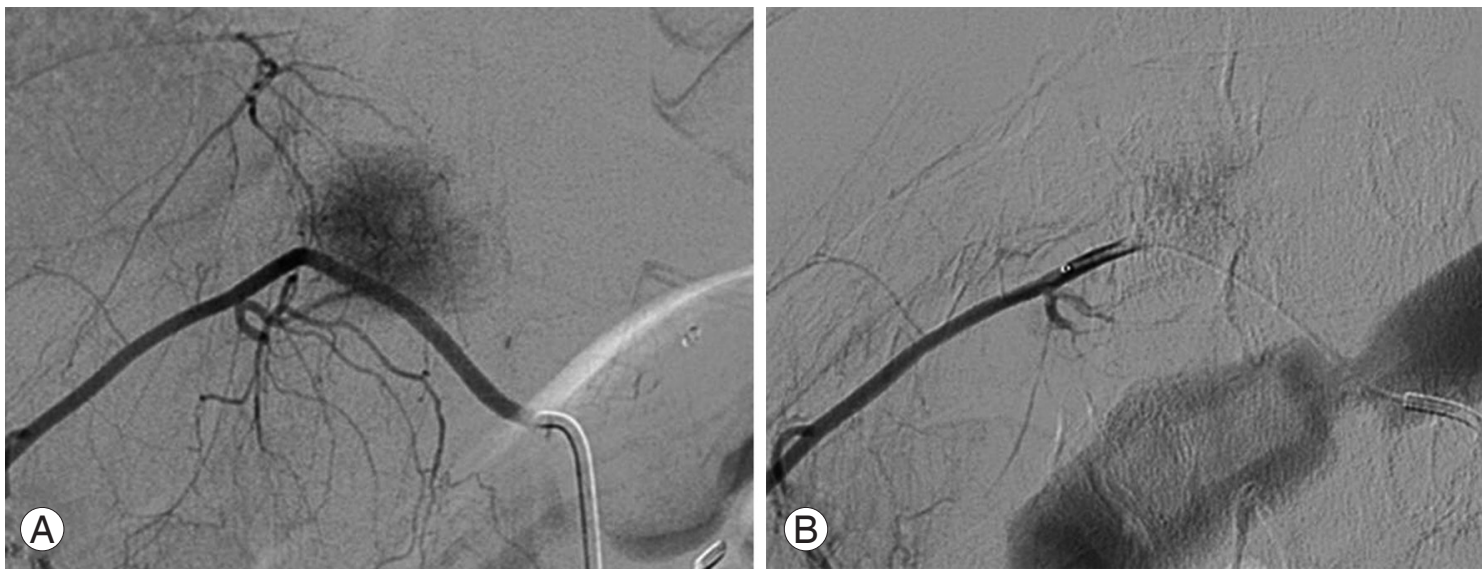

Fig. 7. A 17-year-old female patient with renal cell carcinoma. T11 metastasis was diagnosed. (A) Preoperative segmental artery angiography shows rich vascularity. (B) Tumor vascularity decreased after segmental artery embolization. 


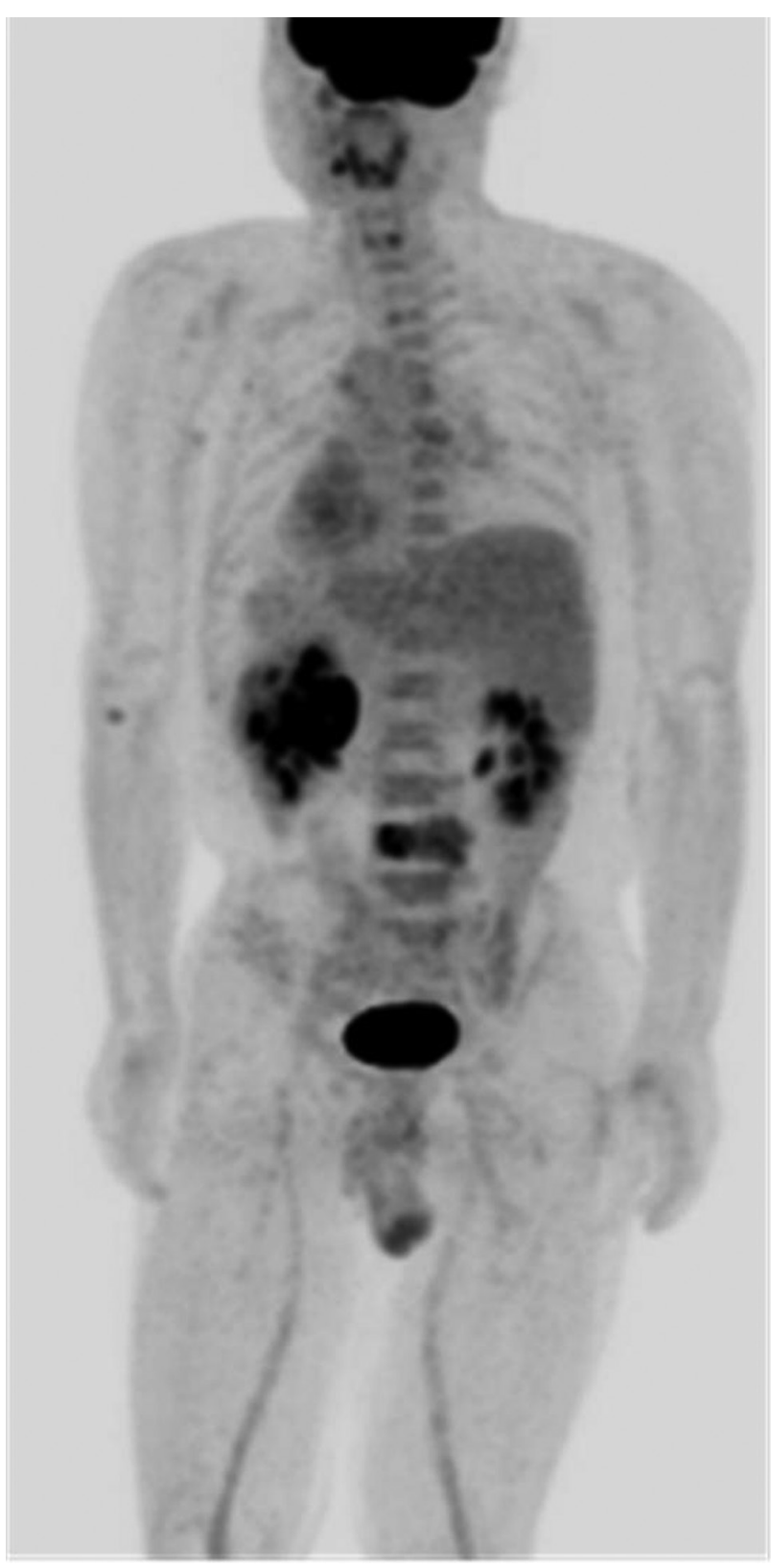

Fig. 8. A 53-year-old male patient without any history of cancer. Lumbar spine magnetic resonance imaging exhibited suspicious metastasis, and positron emission tomography scan revealed increased uptake at left kidney, which is a primary site of metastasis.

clude making a prognosis on possibility of local recurrence and metastasis, selecting a surgical method, and deciding a guideline of adjuvant chemotherapy.

\section{Stage of Musculoskeletal Tumor Society (Enneking stage)}

Enneking stage is the method, which has been used for more than 20 years for staging of benign and malignant tumor [19]. Benign tumor is classified according to the progression pattern of lesions such as, stage $1=$ latent and inactive, stage 2 active but slow growing, and stage $3=$ active and aggressively growing (Fig. 9), while malignant tumor is classified according to histologic grade (I, II), site (A = intracompartment, $\mathrm{B}=$ extracompartment), and metastasis (III). This method is useful in the areas such as extremities, pelvis, and soft tissues, but its application on the spine is not appropriate due to the unclear compartments and unique structure of the spine.

\section{Weinstein-Boriani-Biagini staging system (WBB staging system)}

In an attempt to improve the drawbacks of the Enneking stage, Weinstein et al. developed WBB staging system $[3,8,16]$, which has recently been recognized. According to the WBB staging system, the spine is divided into 12 pieces clockwise on the horizontal plane and then, layers from adjacent tissue to dura is divided into 5 layers in the lateral to medial direction. In case of cervical vertebra, neural foramen has been additionally staged. Sometimes, angiography is required along with $\mathrm{CT}$ and MRI for WBB staging system. The WBB staging system is useful for providing description according to the margin requiring surgical excision. In particular, clock-shaped zone is most significant for setting a scope of en bloc resection of tumor (Fig. 10).

If tumor is localized to zone 4-8, or zone 5-9, at least one pedicle is intact. Therefore, after excision of the posterior element, cauterization of the epidural venous plexus, internal fixation, resection and reconstruction at anterior or posterior vertebral body and internal fixation according to preoperative plan can be conducted. When tumor is limited at zone 3-5 or zone 8-10, axial resection is useful, and in cases of multiple vertebral invasion or rib invasion, resection is also possible. When tumor is limited at zone 10-3, posterior laminectomy and superior and inferior pedicle resection is radically performed and then, lateral dissection is performed to osteotomize and remove the lamina is useful.

\section{Tomita scoring system}

Tomita et al. [6,7] suggested a new and transformed version of Enneking surgical staging, according to anatomical sites and degrees of tumor invaded into the spine (Fig. 11). According to sites and level of invasion, intracompartmental lesion (type 1,2,3), extracompartmental lesion (type 4, 5, 
6), and multiple skip lesion (type 7) are suggested, and this system helps in deciding method of tumor resection. Based on this system, Tomita reported that corpectomy or laminectomy is performed for type 1 , corpectomy or total spondylectomy is performed for type 2 according to the location of lesion, and total spondylectomy is performed for type 3, 4 and 5 using posterior approach, but type 6 and 7 are not surgically indicated.

However, this system is criticized to be mainly based on total spondylectomy rather than partial resection.

\section{Treatment Methods}

The purpose of treating metastatic spine tumor is to attain pain relief and restoration of neural function for enhancing quality of life. Methods of treating metastatic spine tumor include common conservative treatments such as use of analgesics and braces, nonsurgical treatments such as hormon- al therapy, chemotherapy, radiotherapy and steroid therapy, and surgical treatments.

\section{Non operative treatment}

\section{1) Conservative treatment}

In order to relieve severe pain, nonsteroidal anti-inflammatory drugs (NSAIDs) may be used and if not controlled, narcotics may also be used. When mechanical pain develops because of the spinal instability due to tumor, braces may be used as a conservative method for symptom relief, but this is an additional method, which should be used along with other treatment methods.

\section{2) Hormonal treatment}

Hormonal treatments can be used for breast cancer or prostate cancer, which are sensitive to hormone.
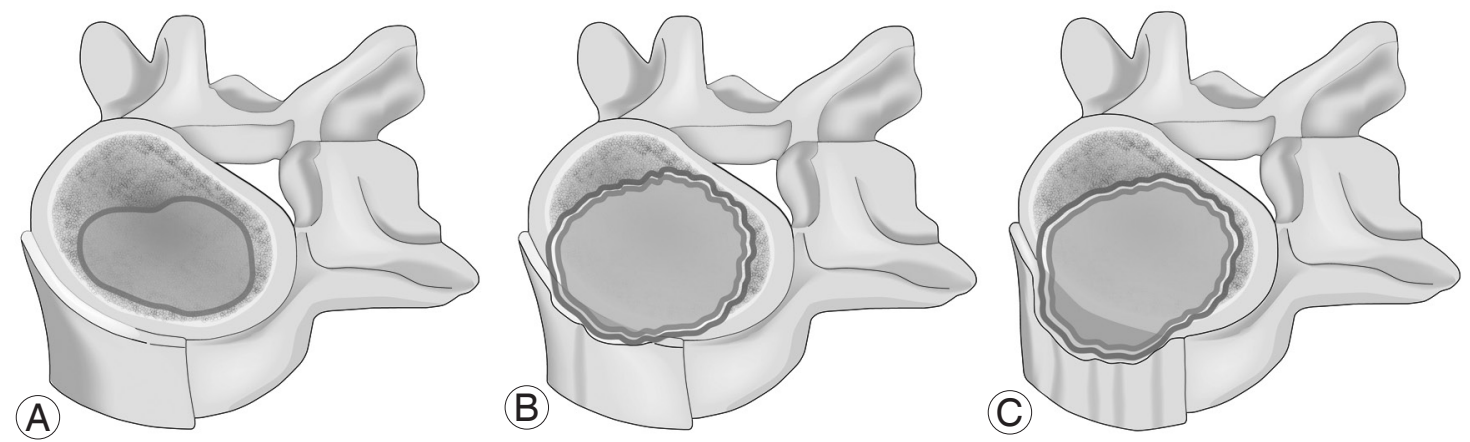

Fig. 9. Enneking stage. (A) S1: latent, inactive. (B) S2: active. (C) S3: aggressive.
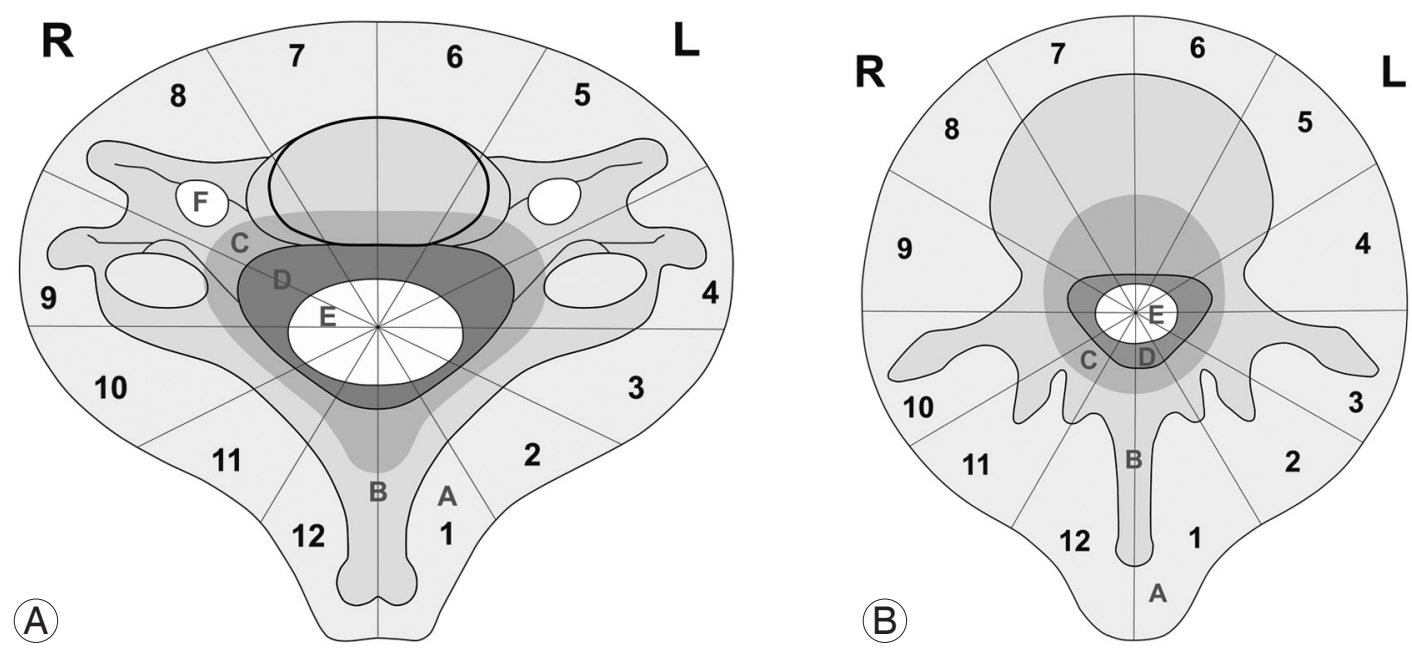

Fig. 10. Weinstein-Boriani-Biagini classification. (A) Cervical spine. (B) Thoracolumbar spine. 


\section{3) Angiography and embolization}

This method is currently used not only for diagnosis of intradural mass, but for obtaining clear understanding on vascular distribution through preoperative angiography to embolize the feeding artery and accordingly, to prevent developments of massive bleeding and paraplegia. In case of inoperable primary or metastatic malignant tumor, chemoembolization, which refers to local injection of chemotherapeutic agent, is usually employed.

\section{4) Radiotherapy}

Radiation energy significantly affects not only normal tissues but also tumor tissues, especially rapidly dividing mitotic tissues and accordingly, functions and structures of normal tissues are preserved while tumor cells are selectively destroyed. Radiation can be typically used for all kinds of musculoskeletal tumors with severe pain, and a considerable reduction in pain is achieved after conducting radiotherapy. Sensitivity of metastasized tumor is different according to the type of primary tumor: high sensitivity with lymphoma and prostate cancer, low sensitivity with colon cancer, renal cell carcinoma and sarcoma, and medium sensitivity with breast cancer. General indications of radiotherapy are: i) Cases of radiosensitive tumor without history of receiving previous radiotherapy. ii) Cases showing stable neurologic deficit. iii) Cases of spinal cord compression by soft tissue in the spinal canal. iv) Cases of spinal instability. v) Cases of inoperable general condition. vi) Cases of disseminated metastatic tumor, and vii) Cases of poor long-term survival.

Since bone marrow suppression and demineralization of bone develops after radiation, patients with spinal instability or risk of compression fracture cannot receive radiotherapy. In addition, vertebral collapse cannot be prevented. As a limitation of radiotherapy, rapidly progressive neurologic deterioration cannot be recovered because immediate spinal decompression is not available. Moreover, neurologic recovery is hardly expected after severe neurologic injury.

5) Corticosteroid and bisphosphonate

In cases where neurologic symptom appears due to spinal

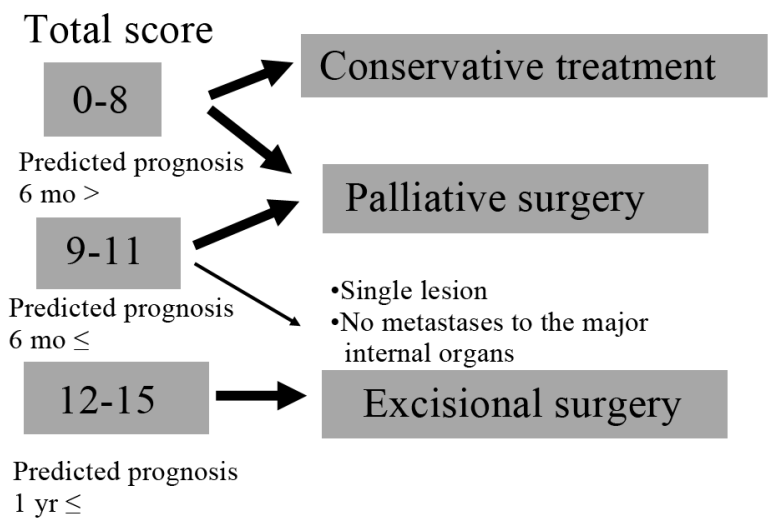

Fig. 12. Strategy of treatment for spinal metastases.

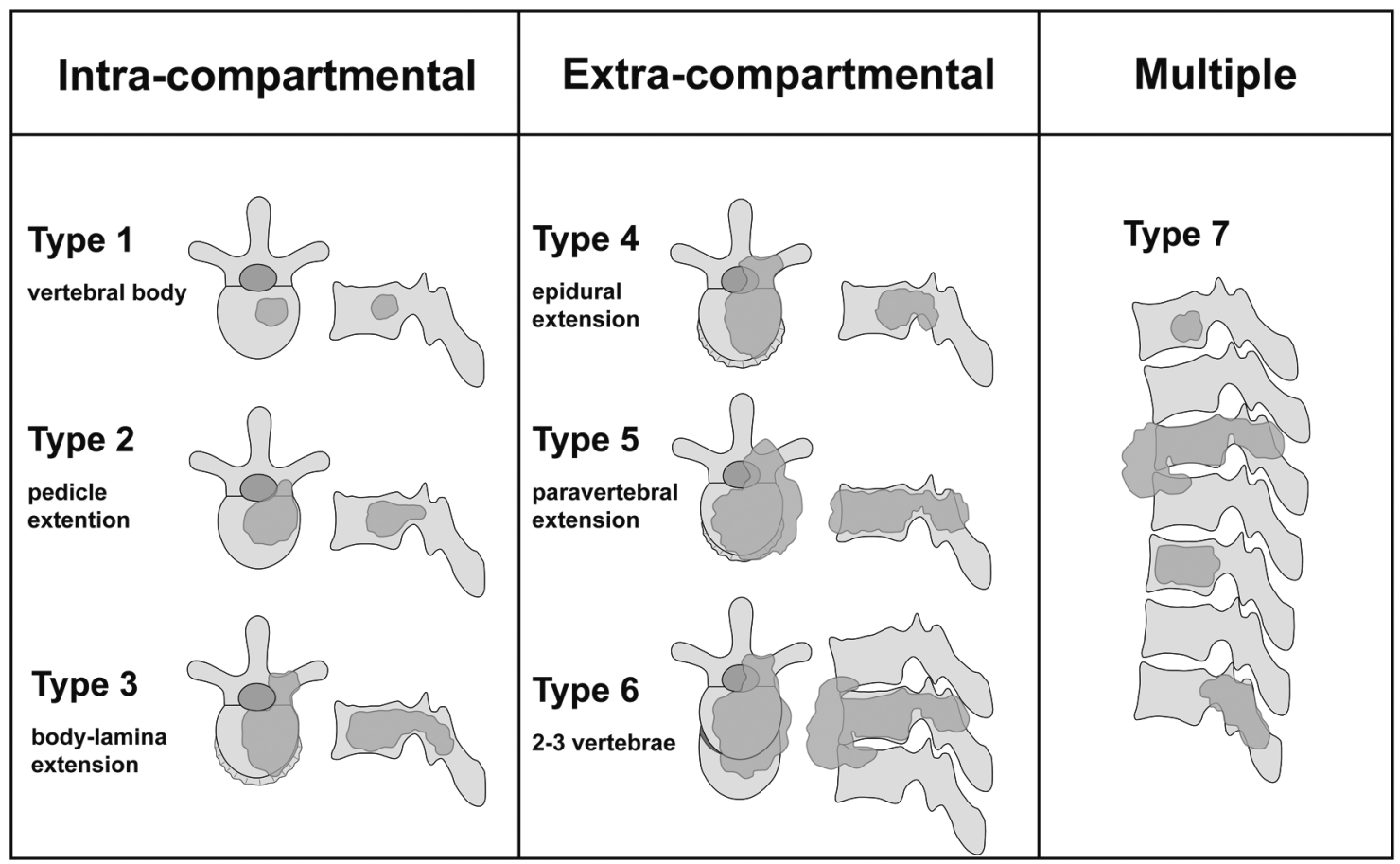

Fig. 11. Tomita classification. 
Table 2. Harrington`s classification and treatment principle

\begin{tabular}{|c|c|c|}
\hline Classification & Neurologic symptom and degree of bone detruction & \\
\hline $\begin{array}{l}\text { Class } 1 \\
\text { Class } 2 \\
\text { Class } 3 \\
\text { Class } 4 \\
\text { Class } 5\end{array}$ & $\begin{array}{l}\text { Minimal neurology } \\
\text { Involvement of bone without collapse or instability and minimal neurology } \\
\text { Major neurologic impairment without spinal instability } \\
\text { Vertebral collapse and instability, without major neurologic impairment } \\
\text { Vertebral collapse and instability with major neurologic impairment }\end{array}$ & \\
\hline \multicolumn{3}{|c|}{ Treatment principle } \\
\hline $\begin{array}{l}\text { Class } 1,2 \\
\text { Class } 3 \\
\text { Class } 4,5\end{array}$ & $\begin{array}{l}\text { Chemotherapy, hormonal therapy, radiotherapy } \\
\text { Radiotherapy with corticosteroid treatment } \\
\text { Surgery }\end{array}$ & \\
\hline Characteristic & & Score \\
\hline \multicolumn{3}{|c|}{ General condition (performance status, $\%$ ) } \\
\hline Poor (10-40) & & 0 \\
\hline Moderate $(50-7$ & & 1 \\
\hline Good $(80-100)$ & & 2 \\
\hline \multicolumn{3}{|c|}{ No. of extraspinal bone metastases foci } \\
\hline 3 or more & & 0 \\
\hline 2 & & 1 \\
\hline 1 & & 2 \\
\hline \multicolumn{3}{|c|}{ Metastases to the major internal organs } \\
\hline Unremovable & & 0 \\
\hline Removable & & 1 \\
\hline No metastases & & 2 \\
\hline \multicolumn{3}{|c|}{ Primary site of the cancer } \\
\hline Lung, osteosarc & , stomach, bladder, esophagus, pancreas & 0 \\
\hline Liver, gallbladd & nidentified & 1 \\
\hline Others & & 2 \\
\hline Kidney, uterus & & 3 \\
\hline Rectum & & 4 \\
\hline Thyroid, breast, & state, carcinoid tumor & 5 \\
\hline \multicolumn{3}{|c|}{ Palsy } \\
\hline Complete (Fran & A, B) & 0 \\
\hline Incomplete (Fra & C, D) & 1 \\
\hline Non (Frankel E & & 2 \\
\hline
\end{tabular}

Criteria of predicted prognosis: total score (TS) 0-8, less than 6 months; TS 9-11, 6 months or more; TS 12-15, 1 year or more.

cord edema caused by metastatic cancer, corticosteroid may be used in order to reduce spinal cord edema. Even though all corticosteroids have anti-edema effects, dexamethasone having comparatively high potency and low salt retention is often recommended. Long-term use of corticosteroid may result in weight gain, insomnia, psychotic symptoms, diabetes mellitus, infection and gastro-intestinal (GI) bleeding, especially in cases of using the drug for 3 weeks or longer, or due to poor nutritional state. According to recent studies on bone metastasis of multiple myeloma, breast cancer, 
prostate cancer, continuous administration of zoledronic acid and the 3rd generation amino-bisphosphonate resulted in reduced skeletal complications [20].

\section{Surgical treatment}

Many authors suggested stages for preparing treatment guidelines of metastatic cancer patients. Harrington $[9,21]$ suggested 5 grades according to bone destruction and neurologic deficit: 1-3 grades requiring nonoperative treatments, and 4-5 grades requiring surgical treatments (Table 2).

Tokuhashi et al. [22] suggested a treatment guideline based on prognosis and life expectancy. Factors representing prognosis include general condition, extra-spinal metastasis, major internal organ metastasis, respectability and primary cancer, which are scored on a 0-15 scale. Patients with scores of 0-8 have less than 6 months life expectancy, and require conservative treatments; patients with scores of 9-11 have more than 6 months life expectancy, and require palliative surgery; and patients with scores of 12-15 have more than 1 year life expectancy, and require excisional surgery (Table 3, Fig. 12).

Tomita et al. [6,7] scored 3 factors such as tumor malignancy, internal organ metastasis, and bone metastasis for prognosis before deciding applicability of surgical treatments (Fig. 13).

In case of pain and neurologic symptoms caused by spinal instability, surgery is more effective than any other methods. Kostuik and Weinstein [23] divided vertebral column into 6
Table 4. Classification of Asdourian et al. [24]

\begin{aligned} & \hline \hline Stage IA Portion of vertebral body marrow is replaced by tumor \\ & IB All of vertebral body marrow is replaced by tumor \\ & Stage IIA Vertebral body collapse occur at one end plate \\ & IIB Vertebral body collapse occur at both end plate \\ & Stage IIIA End stage collapse with kyphotic deformity \\ & IIIB End stage collapse with symmetric collapse \\ & Stage IV Subluxation creates translational deformity \\ & \hline\end{aligned}

segments for assessing instability: presence of instability in case of 3 or more segments invasion, and unstable in case of $20^{\circ}$ or more angular deformity (Fig. 14).

Asdourian et al. [24] suggested a 4-staged spinal deformity caused by spine metastasis of breast cancer to decide treatment guidelines (Table 4).

Taneichi et al. [25] suggested risk factors of vertebral body collapse in case of 100 patients having osteolytic spine lesion. In case of the collapse between T1 and T10, risk is high when $50 \%$ or more of vertebral body erosion is shown, or $25 \%$ or more vertebral body erosion plus costovertebral joint invasion are shown; in case of the collapse between T11 and L5, risk is high when $35 \%$ or more vertebral body erosion is shown, or $20 \%$ or more vertebral body erosion plus posterior element invasion are shown.

As shown above, factors helping in decision making on surgery have been suggested. Surgical indications for metastatic spinal tumor patients are as follows: i) Pain or neurologic symptom due to spinal instability, ii) Pain or neurologic symptom due to direct invasion without spinal

\begin{tabular}{|c|c|c|c|c|c|c|}
\hline \multicolumn{4}{|c|}{ Scoring system } & \multirow{2}{*}{$\begin{array}{l}\text { Prognostic } \\
\text { score }\end{array}$} & \multirow{2}{*}{$\begin{array}{c}\text { Tretment } \\
\text { goal }\end{array}$} & \multirow{2}{*}{$\begin{array}{l}\text { Surgical } \\
\text { strategy }\end{array}$} \\
\hline \multirow[b]{2}{*}{ Point } & \multicolumn{3}{|c|}{ Prognostic factors } & & & \\
\hline & $\begin{array}{c}\text { Primary } \\
\text { tumor }\end{array}$ & $\begin{array}{l}\text { Visceral } \\
\text { mets. }\end{array}$ & mets. & $\begin{array}{l}2 \\
-3\end{array}$ & $\begin{array}{l}\text { Long-term } \\
\text { local control }\end{array}$ & $\begin{array}{l}\text { Wide or } \\
\text { marginal } \\
\text { excision }\end{array}$ \\
\hline 1 & $\begin{array}{c}\text { Slow } \\
\text { growth } \\
\text { (breast, thyroid, } \\
\text { etc.) }\end{array}$ & & $\begin{array}{c}\text { Solitary } \\
\text { or } \\
\text { isolated }\end{array}$ & $\begin{array}{c}4 \\
--- \\
5\end{array}$ & $\begin{array}{l}\text { Middle-term } \\
\text { local control }\end{array}$ & $\begin{array}{l}\text { Marginal or } \\
\text { intralesional } \\
\text { excision }\end{array}$ \\
\hline 2 & $\begin{array}{l}\text { Moderate } \\
\text { growth } \\
\text { (kidney, uterus, etc.) }\end{array}$ & Treatable & Multiple & $\begin{array}{c}6 \\
-- \\
7\end{array}$ & $\begin{array}{l}\text { Short-term } \\
\text { local control }\end{array}$ & $\begin{array}{l}\text { Palliative } \\
\text { surgery }\end{array}$ \\
\hline 4 & $\begin{array}{c}\text { Rapid } \\
\text { growth } \\
\text { (Iung, stomach, etc.) }\end{array}$ & $\begin{array}{c}\text { Un- } \\
\text { treatable }\end{array}$ & & $\begin{array}{c}8 \\
-9 \\
-10\end{array}$ & $\begin{array}{l}\text { Terminal } \\
\text { care }\end{array}$ & $\begin{array}{l}\text { Supportive } \\
\text { care }\end{array}$ \\
\hline
\end{tabular}

Fig. 13. Tomita's scoring system for surgical strategy. mets: Metastases. ${ }^{\text {a) }}$ No visceral mets $=0$ point, ${ }^{\text {b) }}$ Bone mets. incluong spinal mets. 
instability, iii) Pain due to radio-resistant tumor, iv) Pain that is persistent after conservative treatments, v) Local lesion with 1 year or longer life expectancy.

Contraindication of operation includes cases well responding to radiotherapy such as multiple organ metastases, poor general condition, lymphoid or reticuloendothelial system, and spinal metastasis of breast cancer or prostate cancer without any structural abnormality of spine.

\section{Surgical margin}

Terminologies on surgical margin have been used without clear definitions. Clear definitions on terminologies are necessary for evaluating preoperative planning and results (Fig. $15)$.

\section{1) Intra-lesional margin}

Intra-lesional margin means contents of tumor exposed after incision. Intracapsular incision is an incomplete resection showing gross or histological remnant tumor, and extracapsular incision means removal of normal tissues containing tumor, but residual tumor is microscopically present.

\section{2) Marginal margin}

Marginal margin means resecting outer surface of pseudomembrane, which is a reactive tissue of tumor. Microscopic remnant can still be observed. This method is used for treatments of aggressive benign lesion and part of metastatic tumor, and for excision of spinal cord tumor or neuroma.

\section{3) Wide margin}

Wide margin means resection via normal tissues around the tumor. Therefore, the tumor and surrounding area is covered by normal tissues after resection. Even though the whole tumor is resected in a single piece, wide margin is not accomplished if part of the margin is pathologically contaminated by tumor. En bloc resection means a surface covered with normal tissues after tumor has been resected in a single piece.

Marginal margin or wide margin is obtainable in the spine. However, these surgical margins are not always accurately kept due to anatomical characteristics of the spine, and to technical problems.

\section{4) Radical margin}

Radical margin means removing compartments invaded by tumor, and this is basically not indicated in case of the
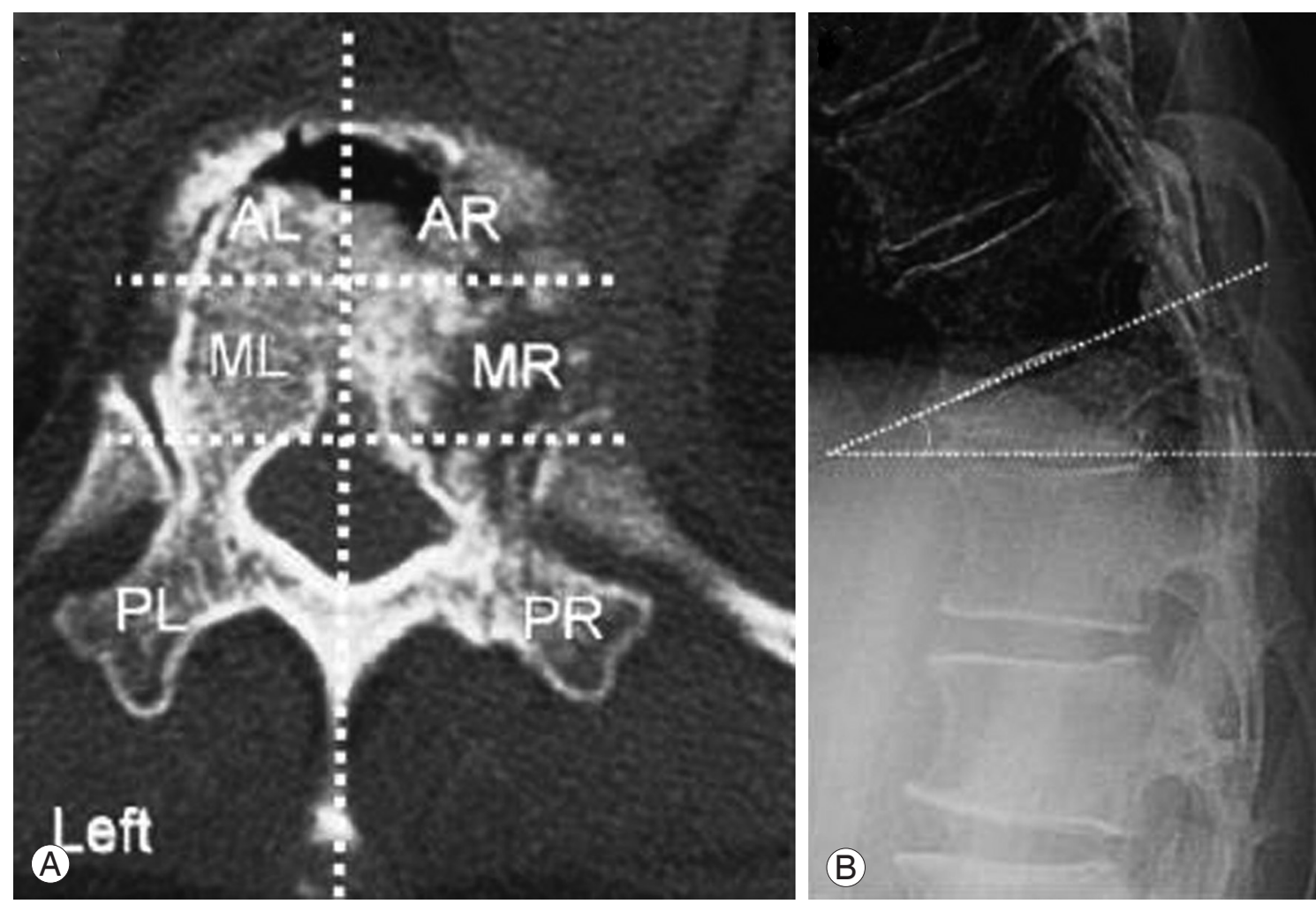

Fig. 14. Evaluation of spinal instability - Kostuik. (A) Six zones. (B) Angular deformity of more than $20^{\circ}$. AL: anterior left, AR: anterior right, ML: middle left, MR: middle right, PL: posterior left, PR: posterior right. 
spine. Even though tumor including spinal cord is resected in a single piece superior and inferior to remote distance, the epidural space is connected from the cranium to coccxys.

\section{Operation method}

1) Spinal decompression

According to approaches and tissues to be resected, operative methods for spinal decompression are classified into anterior corpectomy, posterior laminectomy, and lateralcostotransversectomy. Most suitable method is selected upon

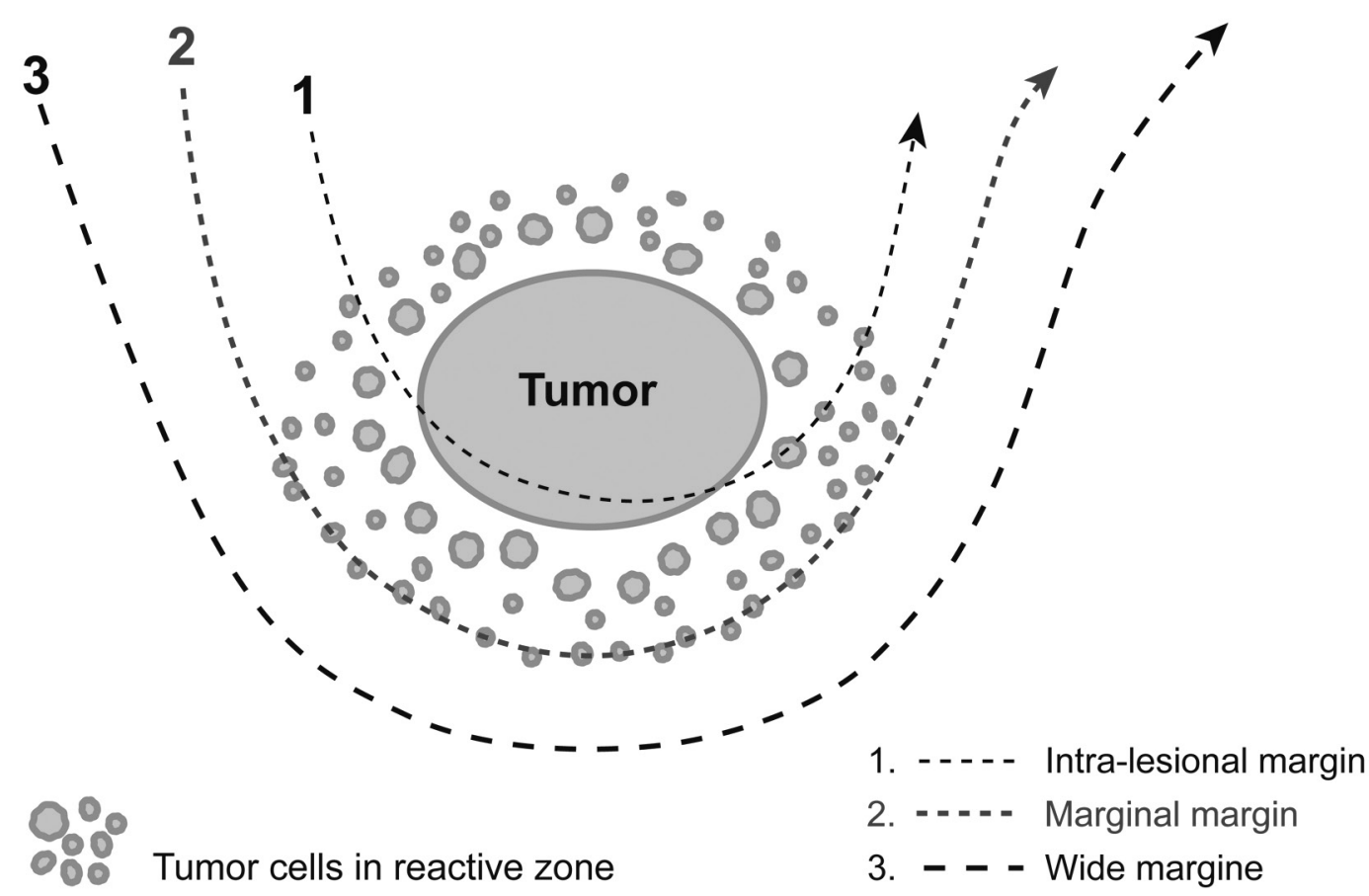

Fig. 15. Surgical margin.
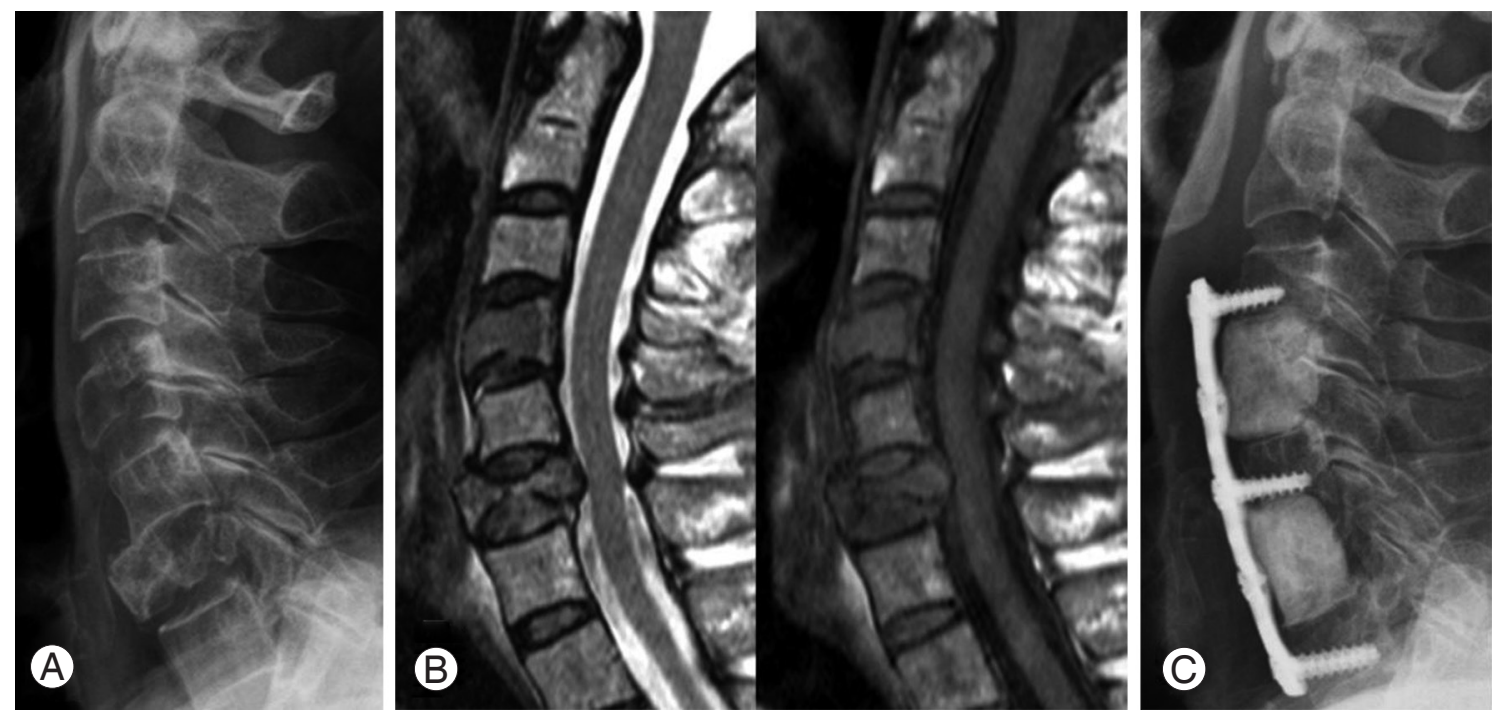

Fig. 16. A case of 70-year-old male patient who visited our hospital with severe neck pain and radiating pain to upper extremities as a chief complaint. The patient had a history of undergoing surgery 5 years ago due to liver cancer. According to plain radiograph (A) and T1- and T2-weighted magnetic resonance imaging photo, (B) pathologic fractures of $\mathrm{C} 4$ and $\mathrm{C} 6$ vertebral bodies are observed. Tokuhashi score was 6, and Tomita score was 7 . After anterior decompression, bone cement augmentation and internal fixation using plates were performed. 
consideration of anatomical location, compression of neural tissue, number of involved segment, necessity of spinal stabilization, and general condition.

Since a metastatic lesion located at vertebral body compresses the spinal cord towards anterior or anterolateral aspect of dura, anterior decompression is useful. However, since bone defect causing instability in the vertebral body is induced, reconstruction and stabilization of anterior column are required. For reconstruction of anterior column, bone cement augmentation or bone graft may be used. Bone ce- ment augmentation reduces risk of non-union, and allows implementation of radiotherapy (Fig. 16).

Posterior decompression through laminectomy is a traditional method of removing neural compression caused by metastatic lesion. This method can be performed on all areas of the spine from the cranium to sacrum, and if necessary, decompression is obtained by removing the pedicle and facet joint. However, other than posterior compression, satisfactory decompression effect is hardly obtainable, and no more effects than radiotherapy are reported.
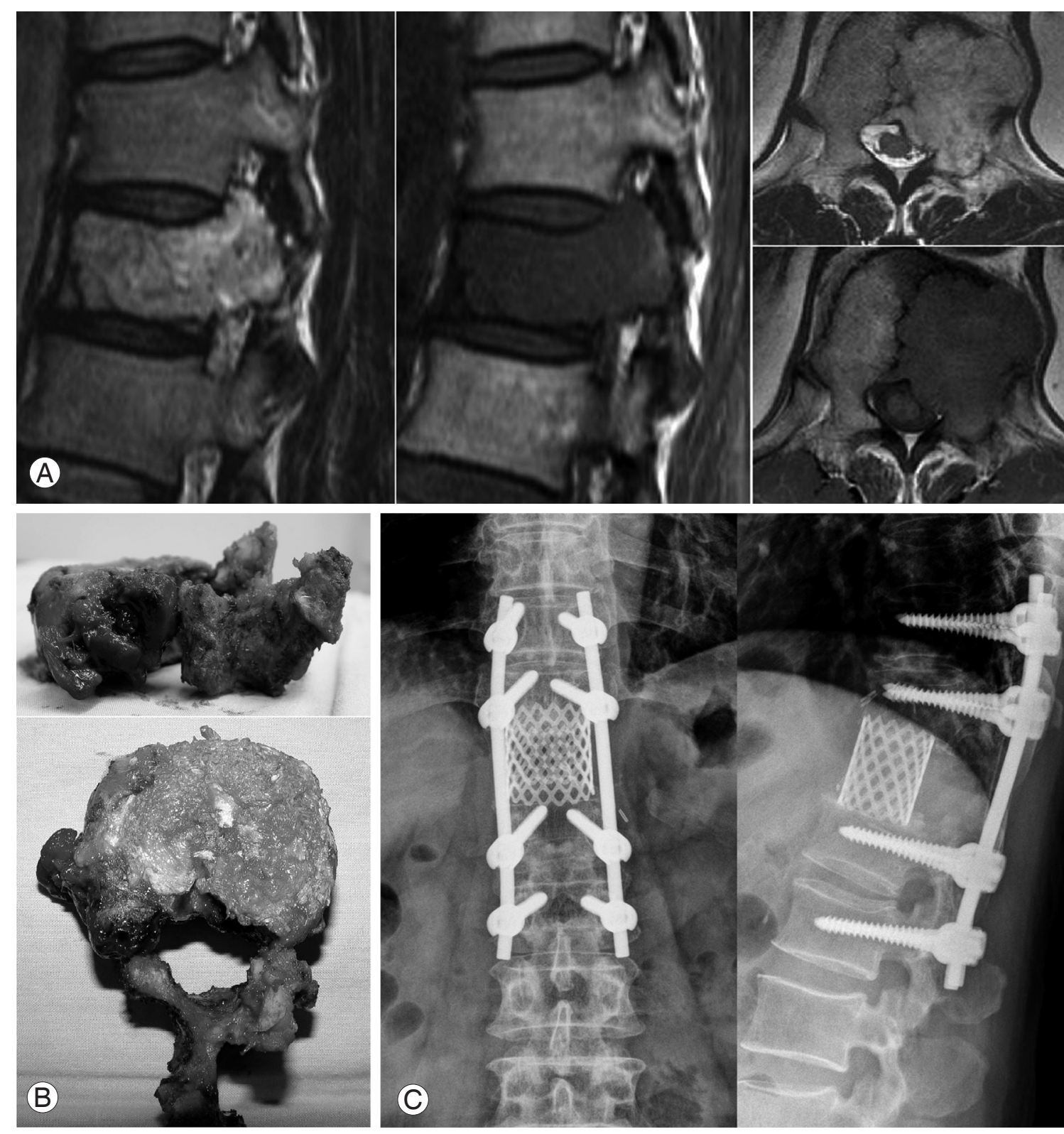

Fig. 17. A 63-year-old male patient with Adenoid cystic carcinoma metastasis to T12. Tokuhashi score was 10 , and Tomita score was 5. (A) T1- and T2-weighted magnetic resonance imaging - Tumor involving the vertebral body and pedicle, but there was no neurologic deficit and the general condition was good. (B) Total spondylectomy was done using combined anterior and posterior approach. (C) Plain radiograph at 2 years follow-up after the operation. 
Using lateral decompression, approach to vertebral body lesion is obtained by removing part of the transverse process and rib in the thoracic level, and by removing facet joint and pedicle in the lumbar level. This method can be implemented when lesion is located at lateral or posterolateral body; all the three columns are invaded; and anterior approach is not appropriate considering general conditions of patients. Decompression effect of posterior decompression is inferior to that of anterior decompression, and anterior reconstruction is difficult due to the poor operation field.

\section{2) Spinal stabilization}

The purpose of spinal stabilization is to reduce already developed deformity, and to recover immediate spinal stability allowing early ambulation. Methods of spinal stabilization vary according to types of tumor, expected treatment result, scope of destruction, general condition and expected survival. Based on the index of spinal instability mentioned before, instrumentation is performed. Basically, anterior column support as well as anterior or posterior instrumentation is performed to obtain adequate fixation. Replacements for anterior column after corpectomy include auto tricortical bone, bone cement, titanium cage, and femur cortical bone allograft. In case of long life expectancy, or after excisional operation, autologous bone graft or bone graft is performed, but in case of palliative surgery for short-term symptomatic improvements, bone cement is used. Multiple level pedicle screw fixation is used in posterior instrumentation, and fixation level is adjusted according to the extent of lesion or postoperative instability.

Posterior stabilization is usually performed together with posterior decompression, but in case that pain caused by instability such as atlantoaxial metastatic lesion is the main symptom, it can be performed independently. Various instruments such as classical Kirschner wire and pedicle screws are used for posterior stabilization, but recently, pedicle screws have been widely used because of multidirectional stability provided by the spinal column.

Since most of the metastatic spinal tumor invades into the vertebral body, corpectomy and anterior stabilization through anterior approach are ideal surgical treatments for metastatic spinal tumor. Approach can be made either right or left in accordance with the location of lesion. In the lower lumbar area, left approach is preferred because inferior vena cava is located at right. Fixators such as metal cage, plate and screw may be used for fixation after removing lesion, and bone graft or bone cement is used for fusion.
In case of Zone IV lesion according to Weinstein stage, or lesion invaded into 3 columns of the vertebral column, combined anterior and posterior stabilization is required (Fig. 17). Total spondylectomy and stabilization through combined anterior and posterior approach are applicable to the thoracic spine and lumbar spine, but rarely applicable to the cervical spine because of the high risk involved in resection of vertebral artery and cervical root. For combined anterior and posterior stabilization, anterior and posterior approach have been simultaneously or sequentially performed in the past, but these days single posterior approach is also employed for total spondylectomy and stabilization.

\section{Conclusions}

Diagnosis of spinal tumor is increasing in accordance with extended life span and development in diagnostic technique, and treatment methods for spinal tumor are also remarkably developing. As early diagnosis is important, possibility of spinal tumor should be always taken into consideration even though the incidence is low. After diagnosis is made, cure of spine tumor, and enhancement of quality of life may be accomplished through cooperation amongst the radiologists, radiation oncologists, oncologists and pain specialists.

\section{REFERENCES}

1. Lee HM. Spinal tumors. In: Suk SI, editor. Textbook of spinal surgery. 2nd ed. Seoul: Newest Medical Company; 2004. p. 491-512.

2. Bohlman HH, Sachs BL, Carter JR, Riley L, Robinson RA. Primary neoplasms of the cervical spine. Diagnosis and treatment of twenty-three patients. J Bone Joint Surg Am 1986;68:483-94.

3. Hart RA, Boriani S, Biagini R, Currier B, Weinstein $\mathrm{JN}$. A system for surgical staging and management of spine tumors. A clinical outcome study of giant cell tumors of the spine. Spine (Phila Pa 1976) 1997;22:177382.

4. Batson OV. The role of the vertebral veins in metastatic processes. Ann Intern Med 1942;16:38-45.

5. Powles TJ, Dowsett M, Easty GC, Easty DM, Neville AM. Breast-cancer osteolysis, bone metastases, and anti-osteolytic effect of aspirin. Lancet 1976;1:608-10.

6. Tomita K, Kawahara N, Baba H, Tsuchiya H, Fujita T, Toribatake Y. Total en bloc spondylectomy. A new sur- 
gical technique for primary malignant vertebral tumors. Spine (Phila Pa 1976) 1997;22:324-33.

7. Tomita K, Kawahara N, Kobayashi T, Yoshida A, Murakami H, Akamaru T. Surgical strategy for spinal metastases. Spine (Phila Pa 1976) 2001;26:298-306.

8. Wong DA, Fornasier VL, MacNab I. Spinal metastases: the obvious, the occult, and the impostors. Spine (Phila Pa 1976) 1990;15:1-4.

9. Harrington KD. Anterior decompression and stabilization of the spine as a treatment for vertebral collapse and spinal cord compression from metastatic malignancy. Clin Orthop Relat Res 1988;(233):177-97.

10. Cybulski GR, Von Roenn KA, D’Angelo CM, DeWald RL. Luque rod stabilization for metastatic disease of the spine. Surg Neurol 1987;28:277-83.

11. Hammerberg KW. Surgical treatment of metastatic spine disease. Spine (Phila Pa 1976) 1992;17:1148-53.

12. Graham W. Bone tumorsed. London: Butterworths, 1966.

13. Keim HA, Reina EG. Osteoid-osteoma as a cause of scoliosis. J Bone Joint Surg Am 1975;57:159-63.

14. Fox MW, Onofrio BM. The natural history and management of symptomatic and asymptomatic vertebral hemangiomas. J Neurosurg 1993;78:36-45.

15. Fraser RD, Paterson DC, Simpson DA. Orthopaedic aspects of spinal tumors in children. J Bone Joint Surg Br 1977;59:143-51.

16. Boriani S, Weinstein JN, Biagini R. Primary bone tumors of the spine. Terminology and surgical staging. Spine (Phila Pa 1976) 1997;22:1036-44.

17. Cuénod CA, Laredo JD, Chevret S, et al. Acute verte- bral collapse due to osteoporosis or malignancy: appearance on unenhanced and gadolinium-enhanced MR images. Radiology 1996;199:541-9.

18. Nakamoto Y, Osman M, Wahl RL. Prevalence and patterns of bone metastases detected with positron emission tomography using F-18 FDG. Clin Nucl Med 2003;28:302-7.

19. Enneking WF, Spanier SS, Goodman MA. A system for the surgical staging of musculoskeletal sarcoma. Clin Orthop Relat Res 1980;(153):106-20.

20. Dhillon S, Lyseng-Williamson KA. Zoledronic acid : a review of its use in the management of bone metastases of malignancy. Drugs 2008;68:507-34.

21. Harrington KD. Metastatic disease of the spine. J Bone Joint Surg Am 1986;68:1110-5.

22. Tokuhashi Y, Matsuzaki H, Oda H, Oshima M, Ryu J. A revised scoring system for preoperative evaluation of metastatic spine tumor prognosis. Spine (Phila $\mathrm{Pa}$ 1976) 2005;30:2186-91.

23. Kostuik JP, Weinstein JN. Differential diagnosis and surgical treatment of metastatic spine tumors. In: Frymoyer JW, editor. The adult spine. New York: Raven Press; 1991. p. 861-88.

24. Asdourian PL, Weidenbaum M, DeWald RL, Hammerberg KW, Ramsey RG. The pattern of vertebral involvement in metastatic vertebral breast cancer. Clin Orthop Relat Res 1990;(250):164-70.

25. Taneichi H, Kaneda K, Takeda N, Abumi K, Satoh S. Risk factors and probability of vertebral body collapse in metastases of the thoracic and lumbar spine. Spine (Phila Pa 1976) 1997;22:239-45. 